\title{
Influencing Factors of Information Channels Adoption of Forest Farmers on Grain for Green Program in Western China
}

\author{
Ma Ning and Yu Jinyu \\ College of Economics and Management, Beijing Forestry University, Beijing \\ 100083, China
}

\begin{abstract}
Forestry ecological projects have a huge impact on the living standard of forest farmers. Thus, information channels forest farmers choose to know about the information of these projects have great importance. The purpose of this study is to find out the main factors that influencing the adoption of these information channels of forest farmers in Western China. Rough set theory is used to solve the problem of main factors reduction. The result shows that total income from working outside, income of forestry, income of agriculture, forestry reforestation subsidy, non-commercial forest subsidy, forest seed subsidy, living expenditure and forest areas are the main factors that influencing the adoption of different channels.
\end{abstract}

Keywords: Grain for Green Program (GGP); information channel; Rough Set Theory $(R S T)$

\section{Introduction}

The forest ecological environment in Western China is very significant since several important forest provinces are located in the western part of China. For many years, researchers have attached a great attention to the construction of ecological environment in Western China. The forestry ecological projects in Western China include Grain for Green Program (GGP), project of non-commercial forest, rocky desertification control project, Natural Forest Conservation Program (NFCP) and so on. In order to promote the implementation of these projects, the Chinese government has announced several different kinds of allowances to forest farmers. These allowances are forestry reforestation subsidy, non-commercial forest subsidy, forest seed subsidy etc.

Among these ecological projects mentioned above, GGP is a major project for achieving sustainable development in China. Since the agriculture civilization, Chinese government had decided to converse tremendous forest areas into farm land in order to solve the problem of food shortage. However, reduction of forestry has resulted to a series of environment problems, such as soil erosion, land desertification, species extinction and so on. Thus, GGP has become a top issue that requires a large range of forest farmers to participate in. Some researchers had pay attention to the returning farm land to forest or grassland in the Yellow River Basin [1] and in different ecological zones of Loess Plateau [2]. In this study, we mainly focus on the implementation status of GGP in western China.

\section{Forestry Research Status}

In previous researches, we carefully studied and analyzed forest farmers' information adoption behavior [3] and features of different types of forest farmers [4] in Fujian province, southeast of China. We got plentiful information about features of forest farmers from these researches which can be applied to the study of forestry ecological projects. What's more, 
researchers have also done a deluge of studies regarding to the practice of forestry ecological projects in China. In the study of Natural Forest Conservation Program (NFCP), Zhang et al. discussed in their Policy Forum "China's forest policy for the 21st century" [5]. And then, Xu et al. pointed out the NFCP focuses on natural forests and affects more than two-thirds of the land area of China; therefore, its success is critical not only to China's forestry and economy, but also to Chinese culture and the global environment [6]. In the study of GGP, some scholars detected the impact of the GGP on the mean annual vegetation cover in the Shaanxi province. The results show GGP resulted in a significant increase of the vegetation cover on farmland in the northern part of Shaanxi province; and in the southern part of the province, no significant increase of the vegetation cover on farmland could be detected [7]. Other scholars applied bi-Logistic Regression model to find the main factors that influence willingness of forest farmers in GGP [8]. Researchers also studied payment for ecosystem services (PES) program in western China, and their statistical analysis shows that participation in GGP has significant positive impacts upon household income. They found that the GGP has not increased the transfer of labor toward non-farming activities as the government expected [9]. The study in Ningxia province shows although targets have been overachieved in some provinces, concern has still emerged regarding the livelihood of farmers after subsidies stop [10]. The assessment of the long-run sustainability of GGP found the main obstacles to the program's sustainability were tenure insecurity and poor land renting rights [11].

Although researchers have studied many aspects of different kinds of forestry ecological projects, the information channels that forest farmers adopt to know about the information about the forestry ecological projects were seldom discussed or studied. As previously mentioned, GGP is one of important forestry ecological projects. These channels will also influence the attitude of forest farmers towards GGP. Thus it is essential to learn about influencing factors of these information channels of forest farmers on GGP in western China.

\section{Methodology}

In this paper, we use Rough Set Theory (RST) to find out the main factors that influence the forest farmers' decision on which channels to choose to know about the information of GGP. We classified the channels into four categories. The first category is the public channel, including newspapers and magazines. The second category is administrative channel from which forest farmers can get information from village committee cadres. The third category is social networks, such as get information from neighbors and relatives. And the forth category is information technology channel, such as Internet. Nowadays, rough set is always used by researchers to solve forestry problems [12]. Researchers have proved that rough set can be used to manage uncertain and incomplete information in the study of forestry [13].

In computer science, a rough set, first introduced by a Polish computer scientist Zdzisław I. Pawlak [14], is a formal approximation of a crisp set (i.e., conventional set) in terms of a pair of sets which give the lower and the upper approximation of the original set. In the standard version of RST, the lower- and upper-approximation sets are crisp sets, but in other variations, the approximating sets may be fuzzy sets.

Let $I=(U, A)$ be an information system (attribute-value system), where $U$ is a nonempty set of finite objects (the universe) and $A$ is a non-empty, finite set of attributes such that $a: U \rightarrow V a$ for every $a \in A$.Va is the set of values that attribute $a$ may take. The information table assigns a value $a(x)$ from $V a$ to each attribute $a$ and object $x$ in the universe $U$.

With any $P \subseteq A$ there is an associated equivalence relation IND $(P)$ : 


$$
\text { IND }(P)=\left\{(x, y) \in U^{2} \mid \forall a \in P, a(x)=a(y)\right\}
$$

The relation IND $(P)$ is called a $P$ indiscernibility relation. The partition of $U$ is a family of all equivalence classes of $\operatorname{IND}(P)$ and is denoted by $U / I N D(P)$ ( or $U / P)$.

If $(x, y) \in I N D(P)$, then $x$ and $y$ are indiscernible (or indistinguishable) by attributes from $P$.

\section{Data Analysis}

\subsection{Variable Selection}

Applied data was collected by questionnaire conducted in Yunnan province, Ningxia province, Guangxi province and Gansu province. These four provinces are all located in the west of China and they are also the provinces with a great number of extensive forest areas in China. Besides, GGP mentioned above is first practiced in these provinces. These features make these provinces to be ideal platforms for researchers whose research area is forestry. The questionnaire consists of multifarious questions which including detail information of family members, detail income, the amount of allowances about different sorts of forestry ecological projects, detail expenditure, forest areas of the family and forest farmers' attitude to the forestry ecological projects. We selected several variables from these questions to analyze the willingness of forest farmers. There are 1011 samples collected. Among them, there are 968 valid samples, accounting for $95.75 \%$ of all the questionnaires received.

\subsection{Building Information System}

In this paper, we selected 25 variables from the questionnaires. A forest information service information system was built by using the huge amounts of data we collected. The system included 968 samples. C means condition attributes, and the $\mathrm{C}$ was composed of $\mathrm{C} 1$, $\mathrm{C} 2, \mathrm{C} 3, \ldots, \mathrm{C} 25$. Detailed information of conditional attributes is shown in table 1. D means decision attributes, as in this paper is which channel that forest farmers choose to know about the detail information of forestry ecological projects. We classified the channels into four categories as introduced before. The value of each category was $\mathrm{d} 1=1, \mathrm{~d} 2=2, \mathrm{~d} 3=3, \mathrm{~d} 4=4$, and detail information is shown in the table 2 . Thus, the whole information system could be shown as follows:

$$
\begin{aligned}
& C=(C 1, C 2, C 3 \ldots C 45) \\
& D=(d 1, d 2, d 3, d 4) \\
& A=\{C 1, C 2, C 3 \ldots C 25, d 1, d 2, d 3, d 4\}
\end{aligned}
$$

Table 1. Conditional Attribute

\begin{tabular}{ll}
\hline Variables & The definition of variables \\
\hline C1 & number of village cadres in the family at present \\
C2 & number of students in the family \\
C3 & sex \\
C4 & age \\
C5 & number of party members \\
\hline
\end{tabular}




\begin{tabular}{ll}
\hline C6 & number of village cadres in the family from past to present \\
C7 & number of forestry workers in the family from past to \\
C8 & total income from working outside \\
C9 & salary \\
C10 & income of forestry \\
C11 & income of agriculture \\
C12 & forestry reforestation subsidy \\
C13 & non-commercial forest subsidy \\
C14 & forest tending subsidy \\
C15 & forest seed subsidy \\
C16 & living expenditure \\
C17 & forest areas owned \\
C18 & total forest areas which have participated in GGP \\
C19 & status of participating in GGP \\
C20 & willingness of participating in GGP \\
C21 & concern about GGP \\
C22 & importance of GGP \\
C23 & satisfaction level of compensation of GGP \\
C24 & satisfaction level on government's GGP policy \\
C25 & satisfaction level on the practice of the projects \\
\hline
\end{tabular}

Table 2. Adoption Channels

\begin{tabular}{ll}
\hline Category & The definition of categories \\
\hline d1 & public channel (newspapers and magazines) \\
d2 & $\begin{array}{l}\text { administrative channel (forest farmers get information from } \\
\text { village committee cadres) }\end{array}$ \\
d3 & $\begin{array}{l}\text { social networks (get information from neighbors and } \\
\text { information technology channel (Internet) }\end{array}$ \\
\hline
\end{tabular}

\subsection{Data Completion}

In practice, most of the information collected by the researchers is often incomplete and defect. We usually named the information system which involved incomplete or defect information as incomplete information system. If simply eliminate the sample with incomplete information, outcome would suffer from wasting large amount of data resources and losing information that hide in the incomplete data. As the information system of this paper was incomplete, proper approach would be completing the defect data. To make this modification, this paper applied conditioned mean completer as the complete algorithm. This method substitutes missing values for numerical attributes with mean value of the mean and mode values which are conditioned to the same decision attributes. Table 3 is an example of 
the detailed calculation steps. The conditional attribute salary of sample No.03 is null. In order to fill it up according to the conditioned mean completer method, we find out the samples that have the same decision attribute value as No.03. The samples are No.02 and No.06, and the salary of each sample is 7500 and 6500 respectively. Thus, the calculating result of salary of No.03 will be the mean value of 7500 and 6500 , which turns out to be 7000 .

\section{Table 3. Incomplete Information System}

\begin{tabular}{lll}
\hline $\begin{array}{l}\text { U(forest } \\
\text { farmers) }\end{array}$ & $\begin{array}{l}\text { Conditional attributes } \\
\text { C9 (Salary) }\end{array}$ & $\begin{array}{l}\text { Decision } \\
\text { attributes } \\
\text { D }\end{array}$ \\
\hline No.01 & 5000 & 1 \\
No.02 & 7500 & 2 \\
No.03 & f1 $=(7500+6500) / 2=7000$ & 2 \\
No.04 & 4500 & 1 \\
No.05 & 6000 & 1 \\
No.06 & 6500 & 2 \\
\hline
\end{tabular}

\subsection{Data Reduction and Results}

In the data mining process, we called the conditional attributes that didn't supply any useful information as redundant attributes. Reduction of attributes means under the condition of keeping knowledge classification ability remain the same level, and obviously, reducing redundant attributes as much as possible would generate statistics that better describe the reality. In the end, we can get a reduction information system. The methodology we applied in the research is Johnson Algorithm of Rosetta software. The final reduction result were been illustrate in the Table 4.

Table 4. Reduction Results

\begin{tabular}{l}
\hline Reduction results \\
\hline total income from working outside, income of forestry, income \\
of agriculture, forestry reforestation subsidy, non-commercial \\
forest subsidy, forest seed subsidy, living expenditure, forest \\
areas $\}$
\end{tabular}

From the table above, it is clearly that there are only 8 key factors that mainly affect the information channels adoption of forest farmers. Although we choose 25 variables at the first place, the reduction results clarify that only some variable related to forest farmers can influence their adoption behavior.

\subsection{Data Analysis}

After examining the reduction results, we summarize the factors that influencing forest farmers' adoption behavior into four aspects. The first aspect is income, which comprises of total income from working outside, income of forestry and income of agriculture. The second aspect is subsidy, including forestry reforestation subsidy, non-commercial forest subsidy and forest seed subsidy. The third aspect is expenditure, mainly consists of living expenditure. And the forth aspect is forest areas. 
We calculated the average mean value of the four different channels according to the four aspects as shown in table 5 below. From the table we can see that some of the category's value is tremendously different from other categories. Thus, we can conclude that the discrepancy in income, subsidy, expenditure or forest areas can influence the adoption behavior about which information channels to choose.

Table 5. Mean Value of Every Category

\begin{tabular}{ccccc}
\hline & Income & Subsidy & Expenditure & Forest Areas \\
\hline 1 & 35104.40 & 1154.54 & 15701.13 & 32.04 \\
2 & 35040.75 & 1150.18 & 14532.64 & 40.09 \\
3 & 27078.12 & 1416.88 & 17460.62 & 30.91 \\
4 & 49438.92 & 2951.85 & 18961.54 & 35.15 \\
\hline
\end{tabular}

\section{Conclusion and Suggestion}

In order to better understand the difference between forest farmers who choose different information channels, we draw a picture about the mean value of every category as shown in Figure 1.

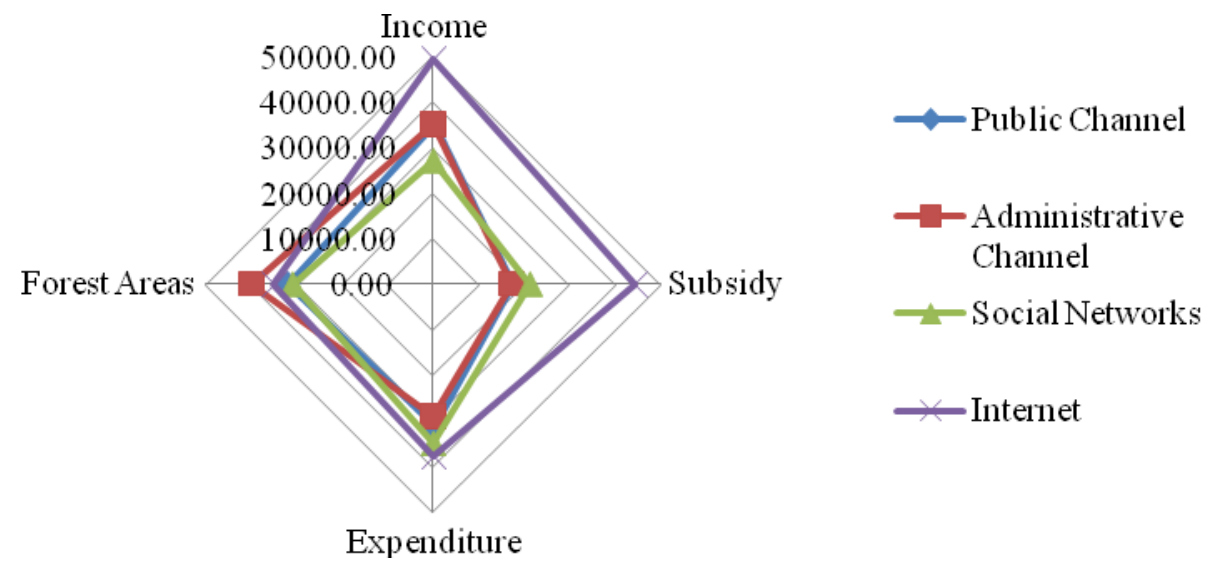

\section{Figure 1. Mean Value of Every Category}

From the Figure 1, we can see a great deal of features about different kinds of forest farmers who adopt diverse channels. Except the forest areas they own are almost at the same level, there is obvious differentiation among other factors. The figures tell us that the forest farmers who choose the forth channel earn much more than people who choose other channels. They also have more allowances than other people. Besides, their expenditure is the highest among different kinds of forest farmers.

It is generally known that forest farmers in China are always poorly educated. Thus, it is understandable that most of them would like to choose three other traditional channels to learn about the information of forestry ecological projects instead of information technology channel (Internet). According to the data of this paper, a small part of forest farmers who adopt the information technology channel show that these people have a better living standard (more income, higher subsidies and larger amount of expenditure). In our previous research, 
we have known about that the forest farmers who know how to use computers and surf on the Internet are always the highly educated ones among them. In this study, forest farmers who choose the information technology channel must be good at using computers. So, the result of this study illustrates that forest farmers with higher education can have a higher level of living standard than other forest farmers.

In order to make sure that forest farmers make the proper decision on whether to participate in GGP, government should popularize the information about GGP. Only if forest farmers get ample information about the market can they produce more ecological and economic benefits. Forest farmers can get the information of GGP through many different ways. These diversity information channels conclude public channel, administrative channel, social networks and information technology channel. Compare to other channels, information technology channel spreads information faster, more accurate, more particular and has a wider range. These characteristics make information technology channel to be the most effective and productive channel.

According to the research results, the features of forest farmers who adopt information technology channel are wealthier, get more allowance than others and have a higher expenditure. However, most of the forest farmers we investigated still rely on the traditional channels.

Generally speaking, there are still millions of poor families in rural China. These disadvantaged households consist of the main part of rural China and their wealth will directly result to the development of Chinese rural area. Chinese government has practiced numerous methods to help these families to increase their income and improve their living standard. While the government still wants to find some other more useful ways to help the disadvantaged households and enhance the ecological and economic benefits of GGP. According to our research results, it is necessary to enhance forest farmers' ability of utilizing information technology for lifting up their living standard. And information technology can also spread the information of GGP rapidly and accurately. Thus, in order to help improve the living standard of these areas and enhance the effect of GGP implementation, the government should put more resources in developing the information technical facilities in rural area, and encourage more forest farmers to use information technology to realize self-enhance.

\section{Acknowledgements}

The research is supported by the Humanities and Social Sciences Planning Fund Supported by Chinese Ministry of Education (No.12YJAZH090), National Social Science Foundation of China (No.11\&ZD042) and Beijing Higher Education Young Elite Teacher Project (No.YETP0777).

\section{References}

[1] S. Wang, Y. Huang and Z. Chen, "Remote Sensing Study of Returning Farmland to Forest or Grassland in the YellowRiver Basin", J Tsinghua Univ (Sci \& Tech) vol. 45, no. 3, (2005), pp. 306-309.

[2] F. Song, G. Yang and Y. Feng, "Research and Establishment of the Multi-effect Assessment Index System of the Returning Farmland to Forest Project in Different Ecological Zones of Loess Plateau", Agricultural Research in the Arid Areas (2007), vol. 25, no. 3, pp. 169-174.

[3] J. Yu and N. Ma, "A Study of the Factors Influencing Forest Farmers Information Technology Adoption", International Journal of Hybrid Information Technology, vol. 7, no. 1, (2014), pp. 241-250.

[4] J. Yu, N. Ma, G. Yin, H. Sun and J. Wen, "Forestry Farmers' Information Demand Characteristics and Classification-Some Practical Views in Fujian Province of China", Journal of Convergence Information Technology, vol. 19, no. 7, (2012), pp.195-202.

[5] P. Zhang, G. Shao, G. Zhao, D. C. Le Master, G. R. Parker, J. B. Dunning Jr. and Q. Li, “China's Forest Policy for the 21st Century", Science, vol. 288, no. 5474, (2000), pp. 2135-2136. 
[6] M. Xu, Y. Qi and P. Gong, “China's New Forest Policy”, Science, vol. 289, no. 5487, (2000), pp. 2049-2050.

[7] H. Zhou, A. V. Rompaey and J. Wang, "Detecting the Impact of the "Grain for Green" Program on the Mean Annual Vegetation Cover in the Shaanxi Province", China Using SPOT-VGT NDVI Data, Land Use Policy (2000), vol. 26, no. 4, pp. 954-960.

[8] S. Ke and T. Zhao, "Empirical Analysis on Factors Influencing on Peasant Households' Willingness of Participation in Conversion of Cultivated Land to Forest Land Program", China Land Science, vol. 22, no. 7, (2008), pp. 27-33.

[9] J. Li, M. W. Feldman, S. Li, and G. C. Daily, "Rural household income and inequality under the Sloping Land Conversion Program in western China", Proceedings of the National Academy of Sciences of the United States of America, vol. 108, no. 19, (2011), pp.7721-7726.

[10] L. Zhang, Q. Tu and A. P. Mol, "Payment for Environmental Services: The Sloping Land Conversion Program in Ningxia Autonomous Region of China", China \& World Economy, vol. 16, no. 2, (2008), pp.6681.

[11] P. Grosjean, "How Sustainable are Sustainable Development Programs? The Case of the Sloping Land Conversion Program in China", World Development, vol. 37, no. 1, (2009), pp. 268-285.

[12] G. Chen, G. Li G, H. Yu and W. Chen, "Rough Attribute Reduction with Application to the Fuzzy Evaluation of Conlfort Level of Wood Based Materials", Scientia Silvae Sinicae, vol. 47, no. 8, (2011), pp.127-133.

[13] W. Tracz and J. Mozgawa, "Rough Sets and the Possibility of Their Use in Forestry", vol. 157, no. 6, (2013), pp. 425-433.

[14] Z. Pawlak, "Rough Sets", International Journal of Computer and Information Sciences, vol. 11, (1982), pp. 341-356. 